\title{
Ethical Standards Help to Define the Medical Toxicologist
}

\author{
Anne-Michelle Ruha ${ }^{1}$
}

Published online: 16 November 2015

(C) American College of Medical Toxicology 2015

The American College of Medical Toxicology (ACMT) recently published an updated Code of Ethics for Medical Toxicologists [1]. The guidelines laid out in this document are said to supplement the Code of Medical Ethics of the American Medical Association, rather than to replace them [2]. This begs the question, "Why do medical toxicologists need their own code of ethics?" Perhaps one reason is because ethical standards are a crucial element that can distinguish medical toxicologists from some other practitioners who offer services related to poisoning.

Medical toxicologists continue to suffer an identity crisis. For example, the distinction between medical toxicologists, forensic toxicologists, environmental toxicologists, and laboratory toxicologists is often unclear to the public. While it may be easy to explain that a medical toxicologist treats patients while a laboratory toxicologist analyzes specimens, it becomes a bit more complicated to explain the difference between a medical toxicologist and another health practitioner who identifies as a 'toxicologist' and claims expertise in poisoning treatment.

While the most obvious factors that differentiate medical toxicologists are specialized training in an ACGMEaccredited fellowship and confirmation of expert-level knowledge through subspecialty board certification by the Medical Toxicology Sub-board of the American Board of Emergency Medicine, a less recognized but incredibly important distinction is the high ethical standard expected of a medical toxicologist. The ACMT Code of Ethics addresses topics that are

Anne-Michelle Ruha

michelle.ruha@bannerhealth.com

1 Banner-University Medical Center Phoenix, 925 E McDowell Rd, 2nd Floor, Phoenix, AZ 85006, USA relevant to physicians across many specialties, such as the physician-patient relationship, expert testimony, and involvement in research and medical education. Situations that may be disproportionately encountered by medical toxicologists, such as treating a suicidal patient or establishing a nontreating relationship during an independent medical examination, can present challenges that the ACMT Code of Ethics may help guide. While all of these topics are important to the ethical practice of medical toxicology, it is the unassuming, short section toward the end of the document on "Use of NonAccepted Therapies" that especially speaks to the differences between the fellowship-trained, board-certified medical toxicologist and a practitioner who promotes poisoning diagnoses and provides services that are not medically justifiable.

Regarding the "Use of Non-Accepted Therapies," the code of ethics states that the medical toxicologist must never use personal gain as a motivating factor in choosing a therapy. Most obviously, personal gain may be financial. In fact, there is great financial opportunity in diagnosing and treating poisoning, regardless of whether poisoning is present. When scientific evidence does not support a test, diagnosis, or treatment, the medical toxicologist must discuss this with the patient honestly and respectfully. This honest discussion can be much more difficult than supporting a belief or previous diagnosis of toxicity and agreeing to initiate or continue an unproven therapy. And it leaves the medical toxicologist without the security of future patient visits and payments. ACMT's participation in the ABIM Foundation's "Choosing Wisely" campaign reflects this position with many of its choices of "Things Providers and Patients Should Question" [3]. ACMT asks providers not to recommend use of dietary supplements, which currently constitute a multi-billion dollar industry in the US. Other ACMT "Choosing Wisely" action items recommend against the use of provoked urine tests to diagnose metal poisoning, the use of unproven detoxification therapies such 
as colon cleansing, and the use of tests to diagnose mold toxicosis - all quite popular practices in the (non-medical) toxicology world today.

Personal gain may also take the form of achieving relative fame, admiration, or the esteem of patients and society. To be able to share "miracle" treatments, or provide diagnoses and "curative" therapies that other doctors cannot, is surely ego bolstering. Yet, as physicians trained in the principles of evidence-based medicine and afforded a high level of trust and respect, we must always remember that our primary responsibility is to the patient. When applying the ethical principle of beneficence to our practice, we hope to obtain the most accurate diagnosis, provide the most effective treatment, and achieve the best outcome for our patients. Still, we must never forget that nonmaleficence, taught to us in medical school as "first do no harm," can be equally important. Sometimes all we should provide is empathy, kindness, and our professional opinion. Choosing not to test and treat when it is in the patient's best interest can demonstrate both the expertise and the ethics of the medical toxicologist.

\section{Compliance with Ethical Standards}

Funding This study received no funding.

Conflict of Interest The author chaired the ACMT and AACT Choosing Wisely Work Group and is a member of the Board of Directors for the American College of Medical Toxicology.

\section{References}

1. American College of Medical Toxicology Code of Ethics for Medical Toxicologists. J Med Toxicol. 2015;11:4.

2. American Medical Association. AMA's Code of Medical Ethics. http://www.ama-assn.org/ama/pub/physician-resources/medicalethics/code-medical-ethics.page?. Accessed 30 Oct 2015.

3. American College of Medical Toxicology and The American Academy of Clinical Toxicology. Five things physicians and patients should question. http://www.choosingwisely.org/societies/americancollege-of-medical-toxicology-and-the-american-academy-ofclinical-toxicology/. Accessed 30 Oct 2015. 